\title{
External Research Funding and Authority Relations
}

\author{
Jonas Krog Lind, Helge Hernes, Kirsi Pulkkinen, \\ and Johan Söderlind
}

Helge Hernes passed away in the Fall of 2018.

Helge Hernes, Kirsi Pulkkinen, and Johan Söderlind contributed equally to this work.

J. K. Lind $(\bowtie)$

Department of Political Science, University of Copenhagen,

Copenhagen, Denmark

e-mail: jkl@ifs.ku.dk

H. Hernes

Department of Political Science \& Management, University of Agder, Kristiansand, Norway

e-mail: romulo.m.pinheiro@uia.no

K. Pulkkinen

Faculty of Social Sciences, University of Lapland, Rovaniemi, Finland

e-mail: kirsi.pulkkinen@ulapland.fi

J. Söderlind

School of Industrial Engineering and Management, KTH Royal Institute of Technology, Stockholm, Sweden

e-mail: johanso2@kth.se

(C) The Author(s) 2019

R. Pinheiro et al. (eds.), Reforms, Organizational Change and

Performance in Higher Education, https://doi.org/10.1007/978-3-030-11738-2_5 


\section{INTRODUCTION}

Over the last three decades, universities have undergone massive transformations (Ferlie et al. 2009). To make universities more productive and attentive to society's needs, governments have introduced new publicmanagement-inspired reforms in most European countries. Although the aims and scope of these reforms and their actual implementation have varied between countries, they all share the same repertoire of reform elements: strengthened management, accountability measures, performance management, and increased competition (Paradeise et al. 2009). One of the central aims of these efforts has been to create more unified and hierarchical organisational actors that are better able to compete in the global market of higher education ( $\mathrm{HE})$, which could especially be carried out by strengthening management at universities (Brunsson and SahlinAndersson 2000; Krucken and Meier 2006; Seeber et al. 2015).

However, not all of the reform elements necessarily point in this direction. As pointed out by Richard Whitley and Jochen Gläser (2014), some trends in the state's attempt at steering the research within universities might go against the trend of strengthening the formal hierarchy. Developments in the funding of research, especially the proliferation of external project funding for research, could have contradictory effects because they are likely to increase the authority of external funding agencies, while decreasing the authority of managers in universities (Whitley 2011; Whitley and Gläser 2014): 'As universities became more concerned to compete for scientific reputations on the basis of their employees' contribution to knowledge, though, and researchers were more able to raise project money from external sources such as state research foundations, the ability of managers to control academics' behaviour has declined' (Whitley and Gläser 2014, 34).

Although Whitley and Gläser state this development as a fact, it should rather be seen as a hypothesis in need of empirical testing, since the authors do not base their conclusions on an empirical investigation of how authority relations play out in a specific empirical context. We intend to explore this hypothesis in a Nordic context by answering the following research question:

How does increasing external research project funding affect the authority over research for managers and researchers in Nordic universities? 
In answering this research question, we draw on the concept of authority relations, which was also first developed by Whitley and Gläser. Authority relations are defined as the 'legitimate power of actors' and address the issue of governance, focusing on the actors involved in the decisions concerning research. In this chapter, we focus specifically on the effect of external research project funding on the authority over research that managers and researchers have.

The chapter is structured as follows: first, we develop the theoretical framework in section "Theory: Authority Relations", presenting and further developing the authority relations concept. Then, we present the methods and data in section "Methods and Data". In section "Changes in External Funding", we explore the policy developments concerning external funding in the case countries. In section "Analysis", we conduct an analysis of the survey results, which is followed by an analysis of the qualitative data on a country basis. In section "Comparison and Discussion", we comparatively discuss the similarities and differences concerning how external funding has affected the authority over research for managers and academics. In section "Conclusion", we conclude the findings of the chapter.

\section{TheOry: Authority Relations}

Authority relations are defined as the 'legitimate power of actors' and revolve around analysing 'the relative authority of a set of interdependent actors' (Gläser 2010, 359); this concept is closely related to the concept of governance. Although governance has been defined in various ways in the literature, a central concern has been how '... different activities and interests are coordinated and regulated' (Whitley 2011, 360). The governance perspective focuses on the systems or modes of governance and hence focuses more on the processes of regulating activities and less so on the specific actors who attempt to exercise authority. The authority relations perspective is both more specific and more inclusive than the governance perspective. As Gläser (2010) states:

It is more specific insofar as it focuses on actors (authoritative agencies) and uses institutional structures and processes of governance as 'background information' on how authority is produced and exercised. At the same time, it is more inclusive because it always includes all actors who have authority concerning a specific decision process regardless of their inclusion in particular governance instruments. (359) 
In the case of this chapter, and in the works of Whitley and Gläser, the specific decision process is about the conduct of research (which we specify further below). One of the central governance mechanisms that has affected authority relations in this area is the proliferation of external project funding in universities, which will be the focus of this chapter.

As defined above, authority is about the legitimate power of actors. However, Whitley and Gläser (2010) do not explicitly define how one should approach and understand power. We will develop an understanding of power that is grounded in the institutional theory as a foundation for the authority relations concept. In the institutional theory, power and authority are not commodities or something an individual can possess; rather, they are a relational phenomenon (Clegg 1989; Lawrence 2008). Therefore, we will not confine our analysis to looking at how authority is formally distributed, but rather, we will focus on how different actors experience the authority relations they find themselves in. According to Thomas Lawrence (2008), power comes in two forms: episodic power, which is 'relatively discrete, strategic acts of mobilization initiated by selfinterested actors' (6), and systemic power, which is the taken-for-granted routines and practices rooted in cultural systems (Lawrence et al. 2012). Hence, episodic power covers all kinds of exercise of power where an individual - or a collective of individuals - purposefully attempts to further his or her interests. This could be accomplished through controlling critical resources (Pfeffer and Salancik 1978) or through having privileged access to knowledge (Clark 1979). However, it could also be engaging in struggles to define what is to be seen as appropriate and true. Hence, episodic power can be used to change institutions and is therefore related to systemic power (Lawrence 2008). Systemic power, though, is when cultural systems and practices become taken for granted and work in less obvious ways. Hence, the exercise of systemic power cannot be attributed to specific actors but still holds power over them.

However, exercising authority over research plays out quite differently for the studied actors in this chapter, and therefore, the concept of authority relations requires some operationalisation. It is likely-and indeed what we partly find in this chapter - that different actors do not want to have authority over the same aspects of research. The researcher wants authority over the actual conduct of research, while managers are interested in authority over the broader direction of research and, as we shall see, are more focused on the authority over research related to resource generation and management in their unit. Furthermore, the studied actors in this 
chapter have to exercise authority in different ways. Although managers (and other actors-in the case of this chapter, the external funders of research especially) will have to exercise their authority over research through others (mainly by affecting researchers' choices or affecting who is allowed to do research), researchers will exercise authority over research by limiting the authority of other actors. This asymmetry comes from the professional knowledge and skills that only researchers have and the basic unpredictability of the scientific endeavour (Clark 1979; Whitley and Gläser 2014). Hence, for researchers, it becomes a question of protecting their research freedom. There is much discussion-yet no agreement-on what research freedom and the broader concept of academic freedom entails (Akerlind and Kayrooz 2003; Altbach 2001). Furthermore, there are different notions of academic freedom among different cultural spheres and countries (Neave 1988). Therefore, we have chosen to use an inductive approach to increase our understanding of what authority over research means for the studied actors in this chapter. More specifically, we focus on the way actors exercise authority over content (research themes and methods used), time (actual time to, and time frames for, doing research), and people (who gets involved in the research). These themes are based mainly on how researchers define the important areas of research authority and will structure the current analysis. Managers also find these themes relevant but emphasise other aspects of them as important to have authority over when compared with researchers. In addition, managers emphasise additional themes that do not fit with the three themes of content, time, and people. Nevertheless, because these themes are more diverse between countries, they will not be subject to an initial categorisation that will structure the analysis. Instead, in the discussion section, we will sum up these and discuss how manager authority in these areas has changed.

\section{Methods And Data}

The chapter uses both the interviews and the survey conducted as part of the FINNUT project (see Chap. 1 of this volume for an in-depth description of the methods used in the FINNUT project). Regarding the interviews, the analysis relied on the FINNUT coding scheme. This chapter mainly draws on two questions in the interview guide that are relevant for this study. For researchers, the question was how much freedom they have in research. For managers, the question was how much freedom they have in making strategic choices regarding the research profile of the unit. 
These questions were purposely phrased to be open, allowing the participants to define their degrees of freedom. In doing so, the interviewees inevitably elaborated on the authority relations they found themselves in.

In the survey, we use the part that relates to autonomy. We use quantitative data to obtain a general understanding of how academics experience their autonomy in research. The qualitative data are used to qualify and make sense of the findings in the quantitative date, which, at first glance, seems to reveal somewhat contradicting findings.

\section{Changes in External Funding}

The overall development in external funding can be seen in Fig. 5.1. The country sections describe the national tendency in more detail. Although the largest percentage of external funding comes from national sourcesmostly research councils and foundations-in recent years, an increasing percentage is coming from the EU. Denmark and Finland have the highest percentage (Denmark had $9.6 \%$ in 1999 and $10.2 \%$ in 2013, while Finland had 6.7\% in 1999 and $13.0 \%$ in 2013) and Norway and Sweden the lowest (Norway had 5.8\% in 1999 and 6\% in 2013, while Sweden had $4.6 \%$ in 1999 and $7.8 \%$ in 2013). ${ }^{1}$ Hence, although their contribution to the increase in external funding is rising, it is still rather marginal, especially in Norway and Sweden.

\section{Denmark}

The spending on research at Danish universities has increased substantially over the years. Since around the year 2000 , spending on research has tripled. Likewise, the percentage of external funding of research has beenmore or less-steadily increasing over the past decades (see Fig. 5.1). The development gained speed during the 1980s, where the percentage more than doubled in a decade, from about $15 \%$ to $30 \%$ of the total research funding. After a period of stagnation during the 1990s and first part of the 2000s, the development took off with the Globalisation Agreement in

\footnotetext{
${ }^{1}$ Organisation for Economic Co-operation and Development (OECD), gross domestic expenditure on research and development (R\&D) by sector of performance and source of funds: https://stats.oecd.org/Index.aspx?DataSetCode=GERD_FUNDS. The most recent data on EU funding on all four countries are from 2013.
} 


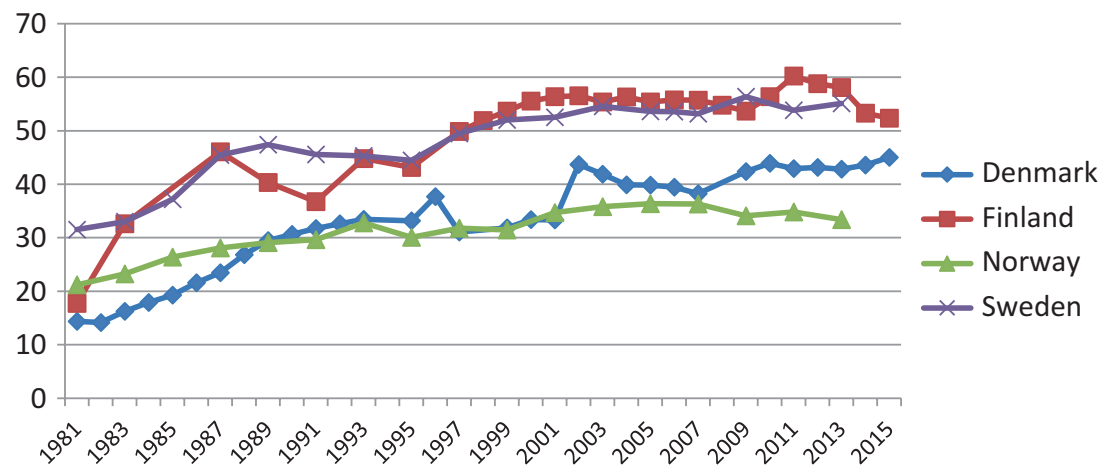

Fig. 5.1 Development in external funding as a percentage of the total funding for research at higher education institutions. Source: Own figure, based on OECD data. To have comparable data, we use OECD data (gross domestic expenditure on R\&D by sector of performance and source of funds): https://stats.oecd.org/ Index.aspx? DataSetCode=GERD_FUNDS. These are for all higher education institutions (HEIs) and are impossible to break down to only universities. However, they should still indicate the general trend because universities by far conduct the most research among higher education institutions. The Organisation for Economic Co-operation and Development (OECD) data were cross-checked with the national available data, which revealed only minor discrepancies for Sweden, Finland and Norway. However, for Denmark, the numbers differ substantially in the years up to 2007. The national data reveal a large jump in the percentage of external funding in 2007. This makes sense because a large number of governmental research institutions with a high percentage of external funding merged with universities, and the globalisation strategy boosted the external funding of universities. However, this jump does not occur in the OECD data. However, the percentages in recent years match well, and therefore, we have, for reasons of comparability, used the OECD data for all countries

2006, which significantly increased the total funding for research, especially external funding (Aagaard 2012).

Organisationally, most competitive funding up until the 2000s was managed by the state research councils (one for each scientific area). In 1992, the Danish National Research Foundation was established, whose aim was to fund centres of excellence (CoEs). Funding was decided by recognised researchers and given to basic research. Hence, the external funding system was still very much in the hands of the academic elite. However, after recommendations from a research committee in 2001, a 
range of reforms, introducing new, more innovation-oriented councils and foundations, changed the organisational landscape for public external funding (e.g., the Council for Technology and Innovation was established, along with the Foundation for High Technology). All these organisational innovations were established to move research more towards applied science and business collaboration (Aagaard and Ravn 2012). In addition to the public funding of research, private foundations slowly developed, especially in recent years, as an important source of research funding. Funding from these sources is, however, problematic from a university management point of view because they do not come with overheads. All in all, the Danish system for external funding is very diverse, with a lot of funders coming in different sizes, with different purposes, and oriented towards different scientific disciplines.

\section{Finland}

The general level of research funding has seen a steady increase for decades, culminating with a doubling of funds between 2000 and 2012, when the levels slightly dropped. The level of external funding grew substantially in the beginning of the 1980s and then again after a few years of decline during the 1990s (see Fig. 5.1). Here, external funding reached levels above $50 \%$ of the total funding for research. In 2009, external funding increased again as a reaction to the new university legislation that took effect on 1 January 2010. The total value of external funding nearly doubled between 2000 and 2016. The general picture is one where the levels of external funding have been more than $50 \%$ for two decades. ${ }^{2}$

With the levels of lump-sum funding increasing only moderately compared with the rising level of demands, the pressure for universities to increase their research funding through external funding grew. To boost the utilisation of research in broader society (including business) more effectively, the government has founded a number of new strategically oriented funding instruments. Organisationally, the shift towards more strategically oriented, competitive funding has increased the role of the Academy of Finland and, to a lesser degree, Business Finland (formerly Tekes, the national innovation agency).

\footnotetext{
${ }^{2}$ Because universities of applied sciences are included in the OECD data, the shift to external funding as the dominating source appears earlier than if numbers were for universities only (Statistics Finland).
} 


\section{Norway}

Funding for research at Norwegian universities has increased substantially in the past few decades, especially since around the year 2000. The level of external funding has also risen steadily but at a slower pace than the other Nordic countries (see Fig. 5.1). The development took off during the 1980s and then again at the end of the 1990s and beginning of the new millennium, after which the development stagnated. The level of external funding is now significantly lower than that of Finland and Sweden.

Among the domestic external funding organisations, the Research Council of Norway is the most important. It was established in 1993 as a merger of five discipline-based councils and has an annual budget of about NOK 9 billion, which is allocated based on discipline, as well as to CoEs and to topic-based research. In 2014, coming up with a long-term plan for research and higher education (Norwegian Ministry of Education 2015), the government announced an increase in research and development appropriations to $1 \%$ of the gross domestic product and to scale up appropriations to research and higher education within six long-term priority areas: seas and oceans; climate, environment, and clean energy; public sector renewal, better and more effective welfare and health, and care services; enabling technologies; innovative and adaptable industry; and world's leading academic groups. Although there is one dominating research council, the funding programmes are quite diverse, and there are regional councils supporting research that has local relevance. Therefore, the system seems as diverse as the other Nordic countries in terms of the types of funding available.

\section{Sweden}

Research funding for Swedish higher education institutions (HEIs) has seen a continuous increase in recent decades, doubling since the year 2000. The percentage of external funding for research has also risen substantially since the early 1980s (see Fig. 5.1). Earlier, external funding was mainly provided by the national research councils and the sectorial research boards, which were established in the post-war era. The research councils operated as an inter-institutional faculty board where researchers could apply for funding. This was also the case for the sectorial research boards, 
which emphasised societal utility and impact as important criteria (Askling 2012, 57).

In 1993, the government introduced a major reform that entailed substantive deregulation and decentralisation. Simultaneously, it also established a number of research foundations. These foundations have various strategic missions and support initiatives such as environmental research and cultural research but also internationalisation and cooperation with industry. In 2001, the Swedish Research Council was established as a new government agency, taking over the activities of the earlier research councils. The trend of an increasing share of external research funds for university research thus continued, reaching levels over $50 \%$, where it has remained since around the year 2000 .

During the years that followed, the national research policy has emphasised quality and excellence. Regarding resource allocation, a number of initiatives have been taken up to effectively concentrate resources for research, often to areas of particular concern for decision-makers (Geschwind and Pinheiro 2017).

\section{The Nordic Countries in Comparison}

Although we can identify some differences in the policy development on external funding, there is substantial congruence in the general trends.

First, the organisation of research funding seems somewhat similar across countries although there are variations. In all countries, there is a variety of different funding opportunities, where some lean towards basic or blue-sky research, and others are more application or innovation oriented. Even the Norwegian and Finnish systems, which both have one dominating research council, are, in reality, diverse systems with many subprogrammes that support research in a variety of ways.

Concerning the development in the level of external funding (see Fig. 5.1), this has at least one common general feature for all countries, namely, the rise of external funding. In the 1990s, a clear picture emerges, one where Sweden and Finland generally lie at 10\% (or more) above Denmark and Norway. However, although Denmark and Norway follow a very similar development from the 1980s and onward, Denmark increases the percentage of external funding substantially from around 2007. Hence, for almost ten years, the picture has been one where Sweden and Finland are at the top, with Denmark following close, and Norway at a level substantially lower than the other Nordic countries. 
Hence, the policy development in the four countries has been very similar in terms of the organisational arrangement of research funding (great diversity) and of growing external funding. This seems to have followed a European script for research policy, where initiatives such as the Lisbon Strategy have pushed for more competition (also in funding) and for research policy being embedded in innovation policy to support economic development in a globalised world (Olsen 2007). The biggest difference between the countries seems to be the level of external funding, where there are substantial differences. The question is how these developments have been interpreted by managers and researchers in the four countries. We will explore this in the next section.

\section{ANALYSIS}

We will begin the analysis by looking at some of the survey data from the FINNUT project. We asked researchers (associate and full professors) in the studied Nordic universities whether they had autonomy regarding the research topic, methods and project partners. ${ }^{3}$ In the context of this chapter, autonomy should be seen as a measure of authority over research. If academics experience high autonomy, we interpret this as others having a low authority over research. The results (see Table 5.1) show that on average, researchers report having fairly large autonomy over research (or authority over research). It is also interesting to note that the differences between countries are not large. On average, the autonomy level is slightly higher across countries for research methods (4.46). This could indicate that research funding mostly affects the topics covered (4.27) and the people who are involved (4.23). This would be consistent with the way external funding usually is managed, where there are often topic restrictions or demands in terms of who should be involved as partners in projects. Requirements in terms of methods are rare. However, it should be noted that the autonomy in research, as measured in this survey item, is of course also determined by factors other than external funding.

However, we also asked researchers whether they experienced any tension between managerial priorities and academic autonomy (Table 5.2). Somewhat contradictory to the high scores on research autonomy, they also score quite high on experiencing these tensions. Although there are

\footnotetext{
${ }^{3}$ We do not have suitable survey data on the experiences of managers in terms of their authority over research.
} 
Table 5.1 Autonomy in research topic, methods and project partners by country (the 'mean' is the mean score on a Likert scale from I 'I strongly disagree' to 5 'I strongly agree')

\begin{tabular}{|c|c|c|c|c|}
\hline \multicolumn{2}{|c|}{$\begin{array}{l}\text { The country in which you } \\
\text { work (for your primary job): }\end{array}$} & \multirow{2}{*}{$\begin{array}{l}\text { I have autonomy } \\
\text { in research } \\
\text { topic. } \\
4.18\end{array}$} & \multirow{2}{*}{$\begin{array}{l}\text { I have autonomy } \\
\text { in research } \\
\text { methods. } \\
4.44\end{array}$} & \multirow{2}{*}{$\begin{array}{l}\text { I have autonomy in } \\
\text { choosing partners for } \\
\text { research projects. } \\
4.21\end{array}$} \\
\hline Denmark & Mean & & & \\
\hline & $N$ & 1616 & 1620 & 1586 \\
\hline & $\begin{array}{l}\text { Std. } \\
\text { deviation }\end{array}$ & 0.969 & 0.809 & 0.977 \\
\hline \multirow[t]{3}{*}{ Finland } & Mean & 4.46 & 4.57 & 4.38 \\
\hline & $N$ & 558 & 557 & 552 \\
\hline & $\begin{array}{l}\text { Std. } \\
\text { deviation }\end{array}$ & 0.829 & 0.785 & 0.904 \\
\hline \multirow[t]{3}{*}{ Norway } & Mean & 4,29 & 4.42 & 4.13 \\
\hline & $N$ & 809 & 806 & 781 \\
\hline & $\begin{array}{l}\text { Std. } \\
\text { deviation }\end{array}$ & 0.923 & 0.864 & 1.098 \\
\hline \multirow[t]{3}{*}{ Sweden } & Mean & 4.39 & 4.50 & 4.31 \\
\hline & $N$ & 357 & 357 & 347 \\
\hline & $\begin{array}{l}\text { Std. } \\
\text { deviation }\end{array}$ & 0.857 & 0.756 & 0.929 \\
\hline \multirow{3}{*}{$\begin{array}{l}\text { Other, please } \\
\text { specify }\end{array}$} & Mean & 4.55 & 4.55 & 4.64 \\
\hline & $N$ & 11 & 11 & 11 \\
\hline & $\begin{array}{l}\text { Std. } \\
\text { deviation }\end{array}$ & 0.522 & 0.688 & 0.674 \\
\hline \multirow[t]{3}{*}{ Total } & Mean & 4.27 & 4.46 & 4.23 \\
\hline & $N$ & 3351 & 3351 & 3277 \\
\hline & $\begin{array}{l}\text { Std. } \\
\text { deviation }\end{array}$ & 0.929 & 0.814 & 0.993 \\
\hline
\end{tabular}

variations between countries, they are quite small. It should be kept in mind that we did not ask specifically about research autonomy but rather about academic autonomy in general. Also, the numbers do not reflect whether researchers experience a tension between the priorities of external funders and their academic autonomy.

Looking at the survey results, a rather murky picture appears where academics, on the one hand, experience quite large autonomy in research but, on the other hand, experience tensions between manager priorities and their academic autonomy. In the qualitative part of the analysis, we will shed light on these seemingly contradictory findings. 
Table 5.2 Tensions between managerial priorities and academic autonomy (the 'mean' is the mean score on a Likert scale from 1 'I strongly disagree' to 5 'I strongly agree')

\begin{tabular}{|c|c|c|}
\hline $\begin{array}{l}\text { The country in which you } \\
\text { primary job): }\end{array}$ & work (for your & $\begin{array}{l}\text { There is a tension between managerial priorities } \\
\text { and academic autonomy. }\end{array}$ \\
\hline \multirow[t]{3}{*}{ Denmark } & Mean & 3.70 \\
\hline & $N$ & 1739 \\
\hline & $\begin{array}{l}\text { Std. } \\
\text { deviation }\end{array}$ & 1.192 \\
\hline \multirow[t]{3}{*}{ Finland } & Mean & 3.70 \\
\hline & $N$ & 773 \\
\hline & $\begin{array}{l}\text { Std. } \\
\text { deviation }\end{array}$ & 1.184 \\
\hline \multirow[t]{3}{*}{ Norway } & Mean & 3.56 \\
\hline & $N$ & 847 \\
\hline & $\begin{array}{l}\text { Std. } \\
\text { deviation }\end{array}$ & 1.225 \\
\hline \multirow[t]{3}{*}{ Sweden } & Mean & 3.60 \\
\hline & $N$ & 530 \\
\hline & $\begin{array}{l}\text { Std. } \\
\text { deviation }\end{array}$ & 1.182 \\
\hline \multirow[t]{3}{*}{ Other, please specify } & Mean & 3.55 \\
\hline & $N$ & 11 \\
\hline & $\begin{array}{l}\text { Std. } \\
\text { deviation }\end{array}$ & 1.036 \\
\hline \multirow[t]{3}{*}{ Total } & Mean & 3.66 \\
\hline & $N$ & 3900 \\
\hline & $\begin{array}{l}\text { Std. } \\
\text { deviation }\end{array}$ & 1.197 \\
\hline
\end{tabular}

In the following sections, using the qualitative data, we will analyse the authority relations regarding research for managers and researchers seen in relation to the growing share of external project funding. First, we will conduct an analysis for each country separately. The analysis will focus on, and be structured around, the authority over research regarding content, time, and people.

\section{Denmark}

External funding plays a huge role in researchers' authority over research. In fact, although especially salient in the natural sciences, external funding 
is almost the sine qua non in contemporary research. On the other hand, researchers generally experience little direct steering of their research. The following quote exemplifies this paradox well: 'On the research side, I have quite big freedom. But what determines what I can do research in is very much controlled by what I can apply and get funding for' (regional, researcher, natural sciences). Managers, on the other hand, experience very little authority over the research being conducted in their units. Even though they formally have the final authority over the applications being sent out, the actual authority is confined to budgetary concerns linked to the research. The general perception is that the competition over external funding has only increased in time.

Danish researchers experience a large amount of freedom in choosing the content of their research. ${ }^{4}$ Most researchers do not experience pressure from managers to change the content of their research. As one researcher puts it, here, commenting on a general lack of academic influence, 'However, it is not that I think our research freedom is suffering. There are no one at the rector or dean level who interferes with which research projects we propose or write or anything' (regional, researcher, social sciences). Managers confirm that they are not directly able to affect content by instructing researchers on the conduct of research, and some state that this is by no means desirable. They see recruiting new staff as the main way to exercise authority over the content and direction of research. Although in some cases there are procedures for the internal evaluation of applications, this is more seen as supporting the creation of good applications, and no one has experienced a situation where managers would reject an application on the grounds of the content (or even quality). However, funders do exercise indirect authority over the content of research. Because of the pressure to obtain funding, some researchers try to align their content with the wishes of funders. This is done in subtle ways, though, as one researcher explains that he tries to read what potential partners in ministries think is interesting at the moment and then tries to make his own research interests fit into this agenda. This kind of influence is, however, the most noticeable when funding comes from private sources or public, non-funding agency funders (e.g., ministries, regions, municipalities, etc.). However, researchers are often able to target their applications to

\footnotetext{
${ }^{4}$ Researchers from former governmental research institutes (GRI) were not included in the qualitative part of the study. These researchers have research assignments more tightly connected to, and often regulated by, contracts with agencies within the central administration. If included, we would perhaps have found other results.
} 
funders who are more suitable for their kind of research to avoid this influence. For example, one researcher mostly acquired funding from hospitals and avoided the national research councils (because it was hard to get funding for cross-disciplinary research), and quite oppositely, another researcher mostly applied to the national research councils because his research was more fundamental and less applied. Hence, because there is a range of different funding options available in the Danish system, better chances for funding can be obtained through some strategic thinking on the part of the researchers.

One of the biggest obstacles to actually doing research is time. First, many researchers complain about a lack of time to do research because they increasingly have other assignments. Writing applications for external funding is one of those tasks-although it differs whether researchers see this as a waste of time or as a part of the research process of refining their ideas (or recognise both). Further enhanced by these developments, it is generally felt that external funding is needed for actually having time to do research. Danish researchers do not automatically have a sabbatical semester where they are free from teaching. Hence, getting funding to be 'bought free' from teaching is important. However, in one case, even though a researcher was 'bought free' from teaching, the researcher still had to teach anyway because of the big teaching load at the department. Of course, managers could, in principle, choose to give sabbaticals to their researchers. However, this would mean more teaching for all staff when they are not on sabbatical. Hence, the authority over research concerning time also has to do with the ministry or state authority over general funding for education.

External funding also affects who gets involved in research. Some funders make explicit that certain types of partners should be included in applications (e.g., businesses, certain public research institutions, stakeholders, etc.). In one case, the funders themselves had so much at stake in the research that they wanted to have carried out that they pushed for a specific person to be included in the project. However, it seems that most researchers actually are able to set the research team and partners in their projects themselves. Managers typically do not have any authority over who gets to apply. However, in cases where a foundation intends to invest heavily in a university, for instance, by granting large donations or donating or cofunding new buildings, the top management is very important, even though the investment is in a specific faculty. Hence, the authority of 
managers seems to be somewhat related to the size and scope of the external funding that enters the university.

Both researchers and managers experience pressure to get funding. This means that on the part of the managers, most are willing to accept all types of funding. This includes what one manager calls 'money from hell' (regional, manager), which is funding with no overhead, high cofunding, and a lot of paperwork. These are problematic and diminish the authority of managers because they bind core funding to the (under)funded projects. Researchers, likewise, experience pressure from managers to get funding. Even if a researcher would accept researching only in his or her spare time (when not teaching), without any external funding, this can be very hard because there is an implicit expectation from management that the researcher should acquire external funding (or at least try to). One interviewee explained how this pressure to secure external funding was also linked to the merit system. In this case, it was made clear that the researcher needed to obtain more funding from prestigious sources, such as the national research councils, to advance to the full professor level.

A problem specific to the natural science faculties and departments is that there is less laboratory assistance available. This is a development that has happened because of increasing external funding. It is now expected that a researcher gets the laboratory assistance needed through external funding. Hence, researchers in the hard sciences almost cannot do research without external funding. However, this goes for all units and universities: it is hard to get internal funding for any activities, and external funding often is important to fund hosting conferences, going on field work, going to international conferences, and so forth.

\section{Finland}

The increasing importance of external funding plays a significant role in the ways researchers and managers perceive their authority over research. Acquiring competitive external funding is strongly emphasised in the Finnish higher education system in general, especially regarding research activities. There is a strong consensus across disciplines and universities that researchers' authority over research has steadily decreased. This development is linked to the rise of external funding, as well as performance-based funding and result-oriented management. The enhanced focus on requiring external funding, which has been pushed by internal performance management, is seen to be problematic when research work is valued first 
and foremost through the economic output, reflecting an attitude of 'If you cannot eat it tomorrow, it is not worth doing' (flagship, researcher, natural sciences). For researchers, this represents a move from science being in the centre of the university to being moved into a periphery position. Strategic thinking has become an irremovable part of academic work, and when planning a research project, researchers must now weigh the risks and consider the possibilities for publication and meeting performance requirements more strategically than before.

For the discussion on Finland, we will begin by focusing on the authority of researchers and managers over the content of the research. Academic staff see the acquisition of external competitive funding as a way to simultaneously secure and risk their freedom: freedom from the management decisions of the university because their work is secured by their external funding, yet a risk to freedom through potentially steered funding. Regarding the latter, the Finnish informants agree that funders have taken a more active role and are increasingly opening thematically focused calls or setting parameters for research areas through participatory processes. Rather than allocating fairly open funding, they now steer the funding more specifically to particular (often societally relevant) fields, for example, around the so-called wicked problems, such as climate change or the ageing society. Through these actions, funders are seen by the academic staff to knowingly limit researchers' authority over research and the space for scientific curiosity. A researcher explains how this is experienced: 'Although we, in principle, have freedom of research and you can choose your areas, the preconditions of today's world define what is wise to do and what is not' (regional, researcher, natural sciences). This development, as well as the more general push from managers to be more strategic thinking, as described above, is drawing the attention of researchers away from the content of research and towards the production of knowledge itself. When requiring external funding becomes an important goal in and of itself, the content of the research is one of the parameters where one can choose to compromise. Yet in general, most Finnish informants agree that a strategic touch is a positive and built-in mechanism in research because it increases quality: 'In research it is automatically so that we don't get the grants to fund research projects if the research is not of high quality and published in good international journals. It's a built-in mechanism in our type of research' (flagship, researcher, natural sciences). Hence, although the increasing push to acquire external funding and the need to think more strategically to some extent limit the authority of researchers over 
their research, it is also seen as an important quality assurance mechanism. Managers have very little direct authority over the content of the research. However, like in the Danish case, their authority is indirect-carried out through the process of hiring researchers that they think match their strategic priorities.

Second, we will now turn to the authority over time. The increasing role of external funding is reflected in the time span that academics have for their work. There is a trend towards results being wanted quicker, leading to academics having to find new ways of working, as seen in the following quote: 'Applied research is emphasised strongly and research has become much more short-sighted. You need to get results at a faster pace. We should be given some time to think a little' (regional, researcher, social sciences). Time has also been coupled with an increase in workloads because researchers are required to allocate more time to the writing of funding proposals. Although being frustrated by the situation, the Finnish informants also see the development as positive, in that it pushes academic professionals to be more strategic in their planning. Drafting competitive proposals for the much-wanted European Research Council funds, for example, is not only time-consuming but also highly demanding. It requires the goal-oriented tapping of their scientific creativity and, in practice, more cooperation with colleagues that can provide valuable input and support. In other words, as the role of external funding has risen, so has a new form of collegiality that can balance competition with support.

Third, we now turn to the authority over research concerning people. Managers have, as in the other cases in Nordic countries, very little authority over who gets involved in the specific projects that researchers bring in through external funding. However, the rising role of external funding affects recruitment practices in another way. Instead of having authority over the people involved in specific research projects, managers exercise authority over the kinds of external funding that are being applied for by hiring faculty staff they believe will get external funding in areas that the managers prioritise. External funding is viewed as an instrument for getting the necessary resources for doing societally significant and scientifically interesting research, as one manager states, 'In many units recruiting is directed so that we can get certain kinds of personnel, we can't have researchers all from the same field, there needs to be diversity' (regional, manager, social sciences). A diverse academic staff within reasonably focused research fields strengthens the chances of building strong institu- 
tional research profiles and research consortia that are able to acquire competitive funding.

\section{Norway}

The growing governmental pressures for increasing externally funded research in Norway over the last decade have brought about important changes in the authority over research for different actors. In the Norwegian higher education system, acquiring external funding has become highly relevant, giving this issue very high legitimacy. This reinforces the tendencies described below, increasing the efforts by researchers to obtain external funding and giving successful universities an enhanced reputation.

First, we will focus on the authority of managers and academics over the content of the research. External funders have demands for the research they are funding: 'You must do something that people are interested in. And you have to do a good research job' (flagship, researcher, natural sciences). However, there seems to be a low degree of direct attempts from external actors to influence the research content: '... and the external actors with whom we cooperate, they have been very professional to understand that they can't interfere in the research processes' (regional, manager).

The relationship between university strategies and authority over research concerning content is a quite complicated one. The informants in the Norwegian study quite consistently report that the university and faculty strategies in recent years have become more specific and operationalised, indicating that managers might exercise authority over research through these strategies. Although the strategies are still characterised by compromises and rhetoric, to a great extent, they emphasise renewed strategic effort to: (a) give direction to the entire institutions; (b) encourage the faculties and departments to collaborate and facilitate more internationalisation; and (c) establish CoEs and similar units, which can be seen as 'soft' attempts at steering research. However, within these frames, there are substantial possibilities for initiatives and interpretations at the faculty, department, research group, and down to the individual researcher level: 'The five strategic fields are considerably wide, so you should be quite unfortunate if you are not included.... But strategies are always used when we argue for priorities' (regional, manager). There are also examples of initiatives that have materialised without being mentioned in the formal 
strategies: 'Our first project within the (mentioning the specific area of commitment) at the university, for example, was in (mentioning the discipline) which was not according to the university's strategy' (flagship, researcher, natural sciences). Such phenomena are, among other things, because of external funding opportunities that in turn may enable enhanced competence, for example, through the recruitment of new scholars.

We will now touch upon how external funding affects managers' and academics' authority over time to do research. Time is the most crucial resource in higher education institutions; the demands for scholars' time are manifold. The pressure towards and within higher education institutions to emphasise external funding both increases and changes these demands. For one thing, a substantial part of scholars' and managers' available time is allocated to write research project applications. When these applications are successful, researchers are expected to conduct this research in addition to their other tasks. In other cases, funding may enable scholars to reduce their teaching load-they are 'bought free'. Because the outcome of the application processes is a crucial factor and is decided upon by actors external to the seeking institutions, the allocation of time is, to a substantial degree, beyond the managers' control, meaning that successful scholars prosper while the situation of others is more challenging. This trend might reinforce a tendency found in some universities where a sharper divide between academics who only teach and academics who only do research is found (Geschwind and Broström 2015). Therefore, the increasing amount of external funding for research seems to increase the authority over research regarding time for academics who are successful in attracting external project funding for research. However, in contrast to the situation in the other Nordic countries, many Norwegian researchers are granted sabbaticals on a periodic basis (although this practice varies between universities and even the units within them). Although the granting of these sabbaticals might depend on one's performance in scientific publishing, thereby indirectly being affected by the ability to attract external funding, sabbaticals will supply researchers with more concentrated time for research.

Finally, we now turn to the authority over research concerning the people involved in the research. Because of different opportunities and traditions between the academic disciplines, a lack of competence, too fragmented research foci, and other factors, there are substantial variations in external funding between faculties, departments, research groups, and 
individual scholars. These variations generate interesting intraorganisational processes. The researcher informants in the Norwegian study who have succeeded in raising external funding report a high degree of congruence between the university and unit strategies and their own academic work. Rather than complaining about the recent developments in the university's managerial systems, these informants seem to take advantage of these processes, especially that they facilitate external funding for them. Thus, these processes are perceived more as possibilities for the scholars and less as threats to the researchers' authority over research. Neither do the informants in our study who do not benefit from substantial external funding seem to make any serious complaints or protests about the developments in the university managerial systems. They do considerable research within the limits of governmental funding, and they report some degree of resignation and rely on universities as loosely coupled entities and the subsequent freedom that follows: 'There is a low degree of leadership. If one withdraws, one is to a high degree able to micromanage one's own working day' (flagship, researcher, social sciences). However, these differences point to external funding as a differentiating mechanism that privileges some groups of researchers over others.

The organisational effects of external funding concerning the people involved in the research thus seem to be subtler, such as when researchers become less dependent on the basic budget and, importantly, even more dependent than before on collaborating with scholars at domestic and international institutions. Managers may be somewhat marginalised in this system of increasing external funding. According to the Norwegian interviews, however, managers do not necessarily perceive these developments as challenging; managers, instead, tend to overemphasise the impact of their managerial roles in other areas and focus on the importance of strategic plans. Additionally, managers may be important facilitators of external funding and may participate in external projects. Following also the strategies of Norwegian universities, CoEs have been established as semiautonomous organisational entities that rely heavily on external funding. Although this is often a strategic ambition that managers have decided to pursue themselves, CoEs paradoxically also represent a challenge for the established university managerial systems, which have very limited authority over whom and in which areas these are established. Hence, external funding seems to reinforce existing patterns among and within higher education institutions; high-performing institutions, centres, and researchers become even more able to provide external funding, while others may 
fall behind, pointing to the Mathew effect commonly found in the sciences (Kwiek 2016).

\section{Sweden}

A clear result from the Swedish interviews is that funding is the most important factor when it comes to authority over research. Funding is essential in enabling any research, and because external actors are allocating a larger share of the resources for research, they are also gaining more authority over research.

We will begin by focusing on the authority of researchers and managers over the content of the research. The most salient way in which influence is exerted over the research process is that researchers adapt to the conditions set by the funders. At times, this may not amount to more than changing the rhetorical framing of the proposed research, which in fact might be seen as a defence strategy known as 'window dressing' (Laudel 2006), but in other instances, it includes major adjustments and compromises to secure funding. One example is a professor at the technical faculty saying that 'you have to try to adapt to whatever is popular to fund at a specific time' (flagship, researcher, engineering science). More severe influences may, for instance, be noted in collaborative research projects, where the goal of companies to develop a product takes precedence over the researchers' desire to produce and disseminate new knowledge. It is also clear how funders may influence research at an institutional level above the individual researcher. Examples primarily include large infrastructural investments that may allow the university to develop their research substantially within particular areas. An example is provided by a research office manager who recalls how a large sum of money was donated to the university for the construction of a house dedicated to design studies. The manager says, 'Of course, you get large effects, since you invest a lot in areas where someone has allocated some hundred million' (flagship, administrator).

Generally, however, there is agreement that the integrity of researchers is quite robust and has not yet been severely challenged by the increase in external funding. Although academics may voice a desire for more authority over research, they also express confidence in their own, as well as their colleagues', ability to maintain their integrity in relation to external actors. A social scientist says, 'You know where to draw the limit, how to dispose your time, and you very often keep in mind what really is important' (flag- 
ship, researcher, social sciences). Several informants also emphasise the institutional safeguards against the risk of being co-opted by external interests. Because a main incentive for academics is to acquire academic qualifications, it is fundamental to pose scientifically interesting questions and publish the results. According to a top manager, it is therefore 'somewhat suicidal' (flagship, manager) to enter too many projects that do not award academic merits, and the system is thus 'to a large extent selfregulating' (flagship, manager). As a further precaution, this manager states that the university has established support structures to ensure that collaboration agreements with external actors are reviewed by lawyers to guarantee the freedom of the researchers to publish their findings. A trend among funders is also the increasing focus on societal expectations, needs, and impact. To some extent, this is appreciated by academics and managers alike in Swedish universities. As expressed by a sociologist, 'If sociology does not matter for society, what then is the point of sociology?' (flagship, manager, social sciences).

We now turn to the authority of managers and researchers over time to do research. Researchers point out that fewer applications are granted funding today and that 'we have to write more applications now' (flagship, researcher, engineering science). Low success rates and general pressure to obtain external funding have thus led to a situation where the process of applying for external funding is more time-consuming than ever before. These new obligations come on top of the other tasks a researcher has, putting pressure on the time to actually do research: 'You feel as an individual researcher that there is a need to have control over all this [calls for external funding] and at the same time do your research, that is tough' (flagship, manager, engineering science). To alleviate some of this pressure, and as a response to the general pressure that managers also experience when it comes to boosting external funding, a strategic priority of universities today is to support researchers in their attempt to acquire external funding. Currently, most universities have a research office that aids in identifying potential funders and in writing applications. At the subinstitutional level, initiatives are also taken to support researchers to acquire funding, as reported by a head of department: 'At the faculty, we have calls, for instance for writing support, article support or application support' (regional, manager, social sciences). These efforts also tie into managing the general insecurity that the increasing share of external funding has created. A top manager notes, 'If large projects end for our researchers, and they cannot find new funding, we have a problem' 
(regional, manager). Fluctuations in revenues from external actors must be balanced by internal funding to maintain the workforce. When a university increases its research activity and when a larger share of this activity is funded by external resources, the risk also increases for the organisation because, to a large extent, this funding is temporary. Working actively to support researchers in their pursuit of external funding is an attempt to manage this risk.

Finally, we now turn to the authority of managers and researchers over the people involved in research. As the share of external funding has increased, managers at various levels note that they now have little influence over the people employed to do research at universities, faculties, and departments. Deciding on projects to fund, and thereby people to promote, is very much in the hands of funders. This also affects the ability of universities to promote quality in research and, in particular, to support up-and-coming researchers, as noted by a top manager. Although successful researchers are rewarded through the acquisition of external funding, researchers with great but yet unrealised potential are often in need of financial support. With scarce resources, however, this is difficult for universities to provide. A final example of how external funding affects the people involved in research is tied more directly to how external funders make concrete demands. A research office manager notes that all external funders demand an impact strategy to make sure that the researchers consider the societal implications of their work. However, some funders do also require active participation from industry and stakeholders, as exemplified in the following quote: 'And of course, that is a huge opportunity to influence the project. And that obviously also affects our research profile' (regional, administrator).

Another trend that reinforces the managers' lack of authority over research, one that cuts across the themes of content, time, and people, is the increasing demands from external funders for cofunding. Because cofunding is required, many internal resources become tied up in research projects, which effectively diminishes the ability of departments to make their own prioritisations. A head of department notes that cofunding deprives researchers of a base resource for research, and a dean points out how this trend undermines the faculty's performance-based resource allocation model (the more cofunding given, the less funding is available to distribute according to the chosen model). Others do, however, state that the less money available to the university management, the more they need to prioritise: 'It forces us to take a strategic stand' (flagship, manager). 
A notable difference in the experiences of managers and academics is that the managers see the consequences of external funding from a broader perspective. Although academics may express a need to frame their research proposals to fit the desires of the funders, managers also reflect on how this affects their authority over research in terms of the ability to prioritise, maintain a healthy working environment, and enhance the quality of the research conducted.

\section{Comparison and Discussion}

The analysis of the influence of external funding on authority over research reveals both many similarities and some differences across the studied countries. However, we should be careful when trying to explain these similarities and (especially) differences by the overall policy development concerning external funding. As the country analyses have also shownand which is an important point in its own right-many other factors interfere with how external funding affects the authority of different actors over research, including, for instance, how much de facto authority managers generally have, how many time constraints there are that can limit research, how Performance-based Research Funding Systems (PRFSs) affect some of the same issues, how important universities strategies are, and so forth. Therefore, how external funding affects authority over research is an intricate matter to analyse. In this section, we will comparatively discuss the country cases and survey data analysed in the previous sections.

One of the broad conclusions we can draw when comparing the country cases is that external funding has become increasingly important for conducting research and has changed the authority of different actors over research. Applying for external funding has become an indispensable part of academic life. The pressure to acquire funding and the competition to obtain these funding sources have increased according to the experiences of both managers and academics. The Finnish, Danish, and Swedish data especially indicate that it is increasingly hard to do research without external funding. Researchers need funding to do what is required of research today, where international cooperation is a necessity, where there is less internal funding for laboratory assistance, and where funding is often necessary to go abroad-on field work or to conferences. But managers also need funding to 'keep the shop running' and experience a huge pressure to increase revenue through external funding. In fact, it seems that obtain- 
ing external funding has become a goal in and of itself for some managers; thus, a budget-maximisation logic seems to have become prevalent. Hence, external funding has become an important general condition for the management and conduct of research.

In the following, we focus on the authority over research for the two analysed groups: managers and researchers. We begin by focusing on the researchers. When taking a first look at the qualitative data, these seem to, in some ways, mirror the somewhat contradictory findings in the survey. When asked directly, researchers generally stress that they have quite large freedom when it comes to research. As the Swedish case shows, the integrity of researchers has not been broken. The same goes for the Norwegian and Danish cases (while the Finnish case stresses the decline of academic freedom to some extent although this is more related to the importance of the strategic priorities of managers). However, when researchers elaborate on the way external funding affects the conditions for research, nuances appear. We find that both the content of the research, the time to do research, and the people involved in doing the research are affected by the increasing amount of external funding.

Regarding content, the Danish, Finnish, and Swedish cases especially show that, at times, researchers adjust the content of their research to meet the demands of funders or to improve their chances of getting funded. Typically, this is done when researchers try to guess what is popular to fund. The Finnish interviews stressed that researchers are learning 'what is wise to do and what is not'. In some cases, university strategies contribute to this effect by pointing out areas where there is more support available. This is especially salient in the Finnish case. Also, the general pressure from managers to obtain external funding further pushes the need to bend to the wishes of external funders.

Regarding time, external funding is increasingly necessary simply to have the time to conduct research. In addition, sometimes, as in the Danish case, there are still time pressures even after a researcher has been 'bought free' in a project. Both the Danish and Swedish cases show how writing applications for external funding are sometimes viewed as a waste of time, preventing researchers from actually doing research. However, some also view this process as an integrated part of the scientific process. The Finnish interviewees especially stressed that time frames have shortened because of external funding and demands for quick results in projects with short deadlines. Management clearly contributes to this process. This calls for more strategic behaviour from researchers. In 
Sweden, Denmark, and Finland, external funding is usually necessary to have the concentrated time required to do research, while at least a proportion of the Norwegian researchers have better opportunities because of regular research sabbaticals that are not directly dependent on external funding. Although the time to do research is probably to a large extent equal between the scientific disciplines, the actual possibility to do research might depend even more on project funding in the natural sciences because researchers in this field usually depend more on external funding to carry out research (with experiments requiring laboratory assistance, expensive equipment, etc.).

Regarding people, the rise of external funding has generally made cooperation between researchers necessary. Most national funders demand cooperation in the project funding they offer. To obtain international funding, as from the EU frame programme HORIZON 2020, international cooperation is often mandatory. However, as the Finnish and Norwegian cases show, this is seen as a natural development in line with how academic norms have developed. However, sometimes, funders are more specific about the partners that will be involved in research projects, as the Swedish and Danish cases illustrate, which limits the authority over research in terms of project partners.

It is important to note that the ways external funding affects the authority over research for researchers are more systemic than episodic in nature. Instead of episodic power, for instance, which would be in the form of direct instruction from managers, the increasing amount of external funding sets up incentives that direct action in more subtle ways through systemic power. A global script pushing for more competition, more industry cooperation to support innovation, demands for societal impact, and so forth has materialised in new funding schemes and in increased competitive funding. The systemic nature of the power exercised by research funders might be one of the explanations for why the survey reveals relatively high research autonomy and why, when asked directly, researchers report great freedom in research: systemic power works in ways that, to a lesser extent, are felt like intrusions into one's agency. Hence, the depth of the qualitative interviews helps uncover the nuances in this authority over research.

However, researchers are not defenceless against these systemic powers. Across the cases, one can identify a range of 'defence mechanisms': first, the academic value of integrity is a systemic power that prevents total surrender to the incentives of funding opportunities. Researchers 'know 
where to draw the limit', as expressed by a Swedish interviewee. It seems that some of the traditional academic values, as made explicit by Robert Merton (1973), are still very much alive. Second, a strategy is to only apply to funders and funding programmes that fit the research agenda of the researcher. Although most clearly expressed in the Danish case, this strategy is likely an option in all the Nordic countries because the funding opportunities are diverse, as the national descriptions of the funding systems have shown. This seems to offer some support for the conclusion found in an article by Richard Whitley and Jochen Gläser (2014), where they hypothesised that high funding flexibility (i.e., diversity in funding opportunities) would lead to more protected space for researchers to conduct research. Third, the Swedish results point to the rhetorical framing of projects, also known as 'window dressing' (Laudel 2006), as a possible defence mechanism. Fourth, as highlighted by the Swedish results, there are also institutional safeguards against being co-opted by external interests in the form of legal advice on collaboration agreements. Hence, safeguarding against external interests is not just a matter for individual researchers but also is sometimes supported by managers.

Looking at the qualitative data, in Finland, the authority over research for researchers seems mostly restricted by the development in external funding, with a little less in Denmark and Sweden, and the least so in Norway. However, it is hard to assess the differences precisely. Although the survey results point only to small differences across countries, there are reasons to believe, as has been argued above, that the qualitative data are better suited for capturing the subtler effects of external funding on the authority over research. This adds to the likelihood that, in reality, there are more differences between countries than the survey results indicate.

We now turn to the authority of managers over research. The national cases mostly point to external funding as a factor that limits the authority of managers over research, at least if focusing on the three themes of content, time, and people. Managers cannot directly affect the content of research, which the Swedish, Danish, and Finnish cases emphasise. Even though they have the formal authority to do so, because managers have to approve applications for external project funding, no one seems to take advantage of this option (or find it appropriate). In this case, it seems that the professional authority of researchers, stemming from the knowledge and skills only they possess, offers researchers a degree of authority over research that limits managers in their use of formal authority. Although this is a structural factor, based on the basic asymmetry between managers 
and researchers in terms of knowledge, there is also an institutional and cultural factor. The fact that managers do not find direct intervention in research appropriate might reflect that the values of academic freedom are also salient among managers. Instead, the authority over the content of research being conducted is exercised mainly through hiring tenured faculty staff. The same is the case regarding people. Managers have little authority over who gets involved in research projects based on external funding; instead, it is through hiring tenured faculty that they exert their influence. In terms of time, managers have a role in setting the basic conditions for time to do research although the opportunities for doing so are heavily circumscribed by the general teaching loads in the specific university or unit. However, because external funding is increasingly necessary to have time for research, the authority of managers in this regard is rather limited.

Instead of trying to affect the conduct of research through the themes of content, time, and people, managers generally seek another type of influence, namely, maximising and securing a steady stream of income. This points to the possibility mentioned in the theory section that managers and researchers might have different priorities concerning the aspects of research that they see as important to exercise authority over.

First, managers attempt to boost their research income by pressuring researchers to obtain funding. In most cases, this pressure is something researchers feel is more implicit than explicit, being an indirect but still unequivocal expectation. However, in the Finnish case, setting targets for units in terms of getting external funding is an example of more explicit measures to increase the pressure to obtain external funding. In this case, but also in the Danish case, linking the success of getting funding to the merit system increases this pressure. This finding might be one of the explanations for why researchers, as shown in the survey data, experience tensions between managerial priorities and academic autonomy. Second, managers also try to increase external funding by setting up offices for research support, offering support for writing funding applications and so forth. Although this can be seen as a strategic choice, it can also be seen as the only choice in a more competitive environment where there are powerful isomorphic pressures (Dimaggio and Powell 1983) to do as other universities have done. Funding has become so important that managers will accept almost all kinds of funding, including funding with no overhead and demands for cofunding. Paradoxically, this is pointed out as problematic, especially in the Danish and Swedish cases, because it ham- 
pers the ability of managers to make strategic prioritisations and because internal funding is tied to these projects. The work of Mats Benner and Gunnar Öquist (2012) partly explains the low level of breakthrough research in Sweden-which is defined as the percentage of articles within the world being in the top $10 \%$ most cited articles — with the high levels of external funding: 'The universities' own priorities are therefore overshadowed and emphasis is laid on how to obtain funding rather than which research priorities to select' (11). Although we offer some credence to the hypothesis that external funding hampers strategic priorities of managers, it is out of the scope of this chapter to assess whether this could be an explanation for lower performance. However, it does seem as though getting external funding has become so important that it has become a goal in and of itself. This finding is consistent with the well-known mechanism that certain activities become institutionalised and thereby infused with value beyond the technical requirements of the task at hand (e.g., of improving the quality of research in universities) (Selznick 1957).

Another theme that cuts across the themes of content, time, and people is the effects of external funding being concentrated in specific units or specific researchers, also known as the Matthew effect (Kwiek 2016; Langfeldt et al. 2015), which, in turn, affects the authority over research for both managers and researchers. As found in the Norwegian and Finnish cases, this seems to reinforce existing patterns: the talented and wellfunded researchers receive even more funding. An example in the Norwegian case is how CoEs give authority to local centre leaders at the expense of other units (which also diminishes the authority of the upper management, hence weakening the organisational hierarchy). A similar effect is also seen in the Swedish case, where large infrastructure investments in one area affect other areas. However, in this case, as in the Danish case of very large external funding donations, the authority of the upper management seems strengthened because top managers in universities need to be involved in these huge donations. These examples of the concentration of resources mean that external funding also creates distinctions within the groups of managers, on the one hand, and among researchers, on the other hand. Furthermore, there are examples of external funding empowering either low-level managers (mostly project funding) or toplevel managers (large donations). As others also have found (Kwiek 2016; Langfeldt et al. 2015), a layer of very well-funded researchers and research leaders - who are less dependent on being in the fields of strategic priority for the university—also seems to have been developed, along with a layer 
of less well-funded researchers who live a more precarious existence. Furthermore, when success in funding acquisition is also connected to career advancements, these divisions of 'winners and losers' become even more pronounced.

\section{CONCLUSION}

We will now return to our research question in which we asked how the increasing amount of external funding affects the authority over research for managers and researchers in Nordic universities.

When focusing on the managers, the first answer is that the external funding of research negatively affects their authority over research; they have very little authority over research within all three themes of content, time, and people. At least, though, their authority is indirect and confined to signalling through strategies and setting broad conditions for research that indirectly affect the research being carried out. Some managers, especially in Sweden, see this as problematic. However, there is another dimension to the authority over research, one where managers exert a stronger influence: the effort to maximise and secure a steady stream of income (a budget-maximisation logic). Although this could be seen as an 'authority dimension' that is two steps away from more substantial directing of research efforts, in terms of the strategic ambitions a manager might have for the type of research being conducted in his or her unit, it is seen by managers as an important avenue for authority over research. This view on what kind of 'authority dimension' to emphasise might also itself be a result of the increasing amount of external funding. When a substantial share of the funding available for research comes from external sources, managing this income becomes more important than the more substantial directing of research efforts.

To assess the consequences of more external funding on managerial authority, one also needs to consider how the counterfactual situation, in which more or all the resources were controlled by managers (external funding being converted to basic funding for universities), would look like. In this situation, managers would be better able to control the direction of research through hiring researchers who fit the local strategies for research. Therefore, in another funding reality, managers' views on what dimensions of research it is important to control might be a different one. The question of whether or not the authority over research for managers has declined, as Whitley and Gläser (2014) have hypothesised, then 
depends on how this authority is defined. However, the findings do indicate-which was certainly expected-that the authority of funders has increased.

Whether the authority of researchers over research has declined or increased as a consequence of the rise of external project funding is also hard to make any firm conclusions about. Although they do, as the survey results indicate, experience quite high general authority over research, a range of mechanisms related to funders and managers reduce this authority. Generally, funders are the most important source of influence over content, time, and people, and the role of managers seems mostly to be a pushing factor for the conditions set by the funders (by pushing for the acquisition of funding, for instance, by linking success to the merit system). However, especially in Finland, managers' influence is so forceful that researchers generally experience a decline in their authority over research. In all countries, the authority of researchers over research seems to vary between successful and less successful researchers. Those who are able to attract large grants generally hold much more authority over research and can create a type of local autonomy from managers. Those with less fortune live a more precarious existence. However, all researchers have at their disposal a range of 'defence mechanisms' that especially balances the authority of the funders.

Obviously, an important question arising from these findings is whether the appropriate balance between external funding and internal funding has been struck in each country. Regarding managers, the Danish, Finnish, and Norwegian results do not show the participants wishing for less external funding. Although they have expressed the troubles emphasised above, most think that competitive external funding is a necessary, basic condition, and they instead focus on the authority dimension related to boosting external funding, as mentioned above. In the case of researchers, most also do not wish for a smaller share of external funding (although the Danish case shows that the researchers in the natural sciences might think more internal funding is needed to have more lab assistance). Quite oppositely, in most cases, researchers think there is too little external funding in the sense that success rates, when applying for external project funding, are too low. That both managers and researchers do not wish for less external funding indicates how institutionalised the current funding allocation system has become. Here, the systemic power of reforms over the last decades has been successful in convincing both managers and researchers that competitive funding is a natural part of science. One explanation for 
this success could be that the competitive nature of the science system (in securing tenure and getting published) aligns well with increasing competitive funding. One can only speculate how another funding situation would affect the authority relations between managers and researchers. However, it is likely that less external funding would lead to less emphasis on the budget-maximisation logic, which is currently strong in the analysed countries - and probably also beyond.

Acknowledgements The data presented in the current volume and individual chapters emanate from a comparative study funded by the Norwegian Research Council under its FINNUT flagship program, a long-term program for research and innovation in the educational sector program. The project number was 237782, and the project was titled 'Does it matter? Assessing the performance effects of changes in leadership and management structures in Nordic Higher Education'.

\section{REFERENCES}

Aagaard, Kaare. 2012. Reformbølgen Tager Form. In Dansk Forskningspolitik Efter Årtusindskiftet, ed. Kaare Aagaard and Niels Mejlgaard, 37-58. Aarhus: Aarhus Universitetsforlag.

Aagaard, Kaare, and Tina Ravn. 2012. Forskningsrådssystemet: Tilføjelser Og Forskydninger. In Dansk Forskningspolitik Efter Årtusindskiftet, ed. Kaare Aagaard and Niels Mejlgaard, 159-194. Aarhus: Aarhus Universitetsforlag.

Akerlind, Gerlese, and Carole Kayrooz. 2003. Understanding Academic Freedom: The Views of Social Scientists. Higher Education Research \& Development 22 (3): 327-344. https://doi.org/10.1080/758482627.

Altbach, Philip G. 2001. Academic Freedom: International Realities and Challenges. Higher Education 41 (1-2): 205-219. https://doi.org/10.102 3/a:1026791518365.

Askling, Berit. 2012. Expansion, Självständighet, Konkurrens. Vart Är Den Högre Utbildningen På Väg? Göteborg: Göteborgs Universitet.

Benner, Mats, and Gunnar Öquist. 2012. Fostering Breakthrough Research: A Comparative Study. Stockholm: The Royal Swedish Academy of Sciences.

Brunsson, Nils, and Kerstin Sahlin-Andersson. 2000. Constructing Organizations: The Example of Public Sector Reform. Organization Studies 21 (4): 721-746. https://doi.org/10.1177/0170840600214003.

Clark, Burton R. 1979. The Many Pathways of Academic Coordination. Higher Education 8 (3): 251-267. https://doi.org/10.1007/BF00137211.

Clegg, Stewart. 1989. Frameworks of Power. London: SAGE Publications Ltd. 
Dimaggio, Paul J., and Walter W. Powell. 1983. The Iron Cage Revisited: Institutional and Collective Rationality in Organizational Fields. American Sociological Review 48 (2): 147-160. https://doi.org/10.2307/2095101.

Ferlie, Ewan, Christine Musselin, and Gianluca Andresani. 2009. The Steering of Higher Education Systems: A Public Management Perspective. In University Governance - Western European Comparative Perspectives, ed. Catherine Paradeise, Emanuela Reale, Ivar Bleiklie, and Ewan Ferlie, 1-19. Dordrecht: Springer. https://doi.org/10.1007/s10734-008-9125-5.

Geschwind, Lars, and Anders Broström. 2015. Managing the Teaching-Research Nexus: Ideals and Practice in Research-Oriented Universities. Higher Education Research and Development 34 (1): 60-73. https://doi.org/10.1080/072943 60.2014 .934332 .

Geschwind, Lars, and Rómulo M. Pinheiro. 2017. Raising the Summit or Flattening the Agora? The Elitist Turn in Science Policy in Northern Europe. Journal of Baltic Studies 48 (4): 513-528. https://doi.org/10.1080/016297 78.2017.1305178.

Gläser, Jochen. 2010. From Governance to Authority Relations? In Reconfiguring Knowledge Production: Changing Authority Relationships in the Sciences and Their Consequences for Intellectual Innovation, ed. Richard Whitley, Jochen Gläser, and Lars Engwall, 358-370. Oxford: Oxford University Press. https:// doi.org/10.1093/acprof:oso/9780199590193.003.0012.

Krucken, George, and Frank Meier. 2006. Turning the University into an Organizational Actor. In Globalisation and Organisation: World Society and Organisational Change, ed. Gili S. Drori, John W. Meyer, and Hokyu Hwang, 241-257. Oxford: Oxford University Press. https://doi.org/10.1017/ CBO9781107415324.004.

Kwiek, Marek. 2016. The European Research Elite: A Cross-National Study of Highly Productive Academics in 11 Countries. Higher Education 71 (1): 379-397. https://doi.org/10.1007/s10734-015-9910-x.

Langfeldt, Liv, Mats Benner, Gunnar Sivertsen, Ernst H. Kristiansen, Dag W. Aksnes, Siri Brorstad Borlaug, Hanne Foss Hansen, Egil Kallerud, and Antti Pelkonen. 2015. Excellence and Growth Dynamics: A Comparative Study of the Matthew Effect. Science and Public Policy 42 (5): 661-675. https://doi. org/10.1093/scipol/scu083.

Laudel, Grit. 2006. The Art of Getting Funded: How Scientists Adapt to Their Funding Conditions. Science and Public Policy 33 (7): 489-504. https://doi. org/10.3152/147154306781778777.

Lawrence, Thomas B. 2008. Power, Institutions and Organizations. In The SAGE Handbook of Organizational Institutionalism, ed. Royston Greenwood, Christine Oliver, Roy Suddaby, and Kerstin Sahlin, 170-197. London: SAGE Publications Ltd. 
Lawrence, Thomas B., Namrata Malhotra, and Tim Morris. 2012. Episodic and Systemic Power in the Transformation of Professional Service Firms. Journal of Management Studies 49 (1): 102-143. https://doi.org/10.1111/j.14676486.2011.01031.x.

Merton, Robert. 1973. The Sociology of Science: Theoretical and Empirical Investigations. Chicago: The University of Chicago Press.

Neave, Guy. 1988. On Being Economical with University Autonomy: Being an Account of the Retrospective Joys of a Written Constitution. In Academic Freedom and Responsibility, ed. Malcolm Tight, 31-48. Buckingham: Open University Press.

Norwegian Ministry of Education. 2015. Long-Term Plan for Research and Higher Education. Report.

Olsen, Johan P. 2007. The Institutional Dynamics of the European University. In University Dynamics and European Integration, ed. Peter Maassen and Johan P. Olsen, 25-54. Dordrecht: Springer. https://doi.org/10.1007/978-14020-5971-1_2.

Paradeise, Catherine, Emanuela Reale, and Gaële Goastellec. 2009. A Comparative Approach to Higher Education Reforms in Western European Countries. In University Governance: Western European Comparative Perspectives, ed. Catherine Paradeise, Emanuela Reale, Ivar Bleiklie, and Ewan Ferlie, 197-225. Dordrecht: Springer Netherlands. https://doi.org/10.1007/978-1-40209515-3_9.

Pfeffer, Jeffrey, and Gerald R. Salancik. 1978. The External Control of Organizations: A Resource Dependence Perspective. New York: Harper and Row. https://doi. org/10.2307/2231527.

Seeber, Marco, Benedetto Lepori, Martina Montauti, Jürgen Enders, Harry de Boer, Elke Weyer, Ivar Bleiklie, et al. 2015. European Universities as Complete Organizations? Understanding Identity, Hierarchy and Rationality in Public Organizations. Public Management Review 17 (10): 1444-1474. https://doi. org/10.1080/14719037.2014.943268.

Selznick, Philip. 1957. Leadership in Administration: A Sociological Interpretation. New York: Harper \& Row.

Whitley, Richard. 2011. Changing Governance and Authority Relations in the Public Sciences. Minerva 49 (4): 359-385. https://doi.org/10.1007/ s11024-011-9182-2.

Whitley, Richard, and Jochen Gläser. 2014. The Impact of Institutional Reforms on the Nature of Universities as Organisations. In Organizational 


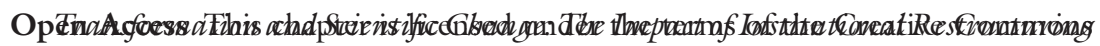

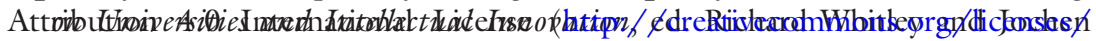

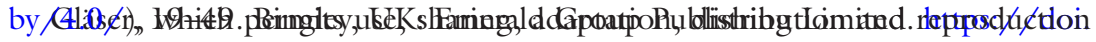

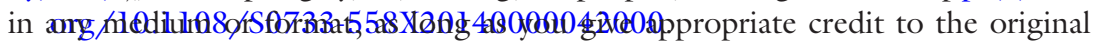
author(s) and the source, provide a link to the Creative Commons licence and indicate if changes were made.

The images or other third party material in this chapter are included in the chapter's Creative Commons licence, unless indicated otherwise in a credit line to the material. If material is not included in the chapter's Creative Commons licence and your intended use is not permitted by statutory regulation or exceeds the permitted use, you will need to obtain permission directly from the copyright holder.

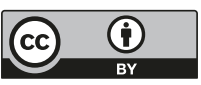

